\title{
Creation of a Neovagina by Laparoscopic Modified Vecchietti Technique: Anatomic and Functional Results
}

\section{Criação de neovagina pela técnica de Vecchietti laparoscópica modificada: resultados anatómicos e funcionais}

\author{
Eduardo Baptista ${ }^{1}$ Giselda Carvalho $^{1} \quad$ Carlos Nobre $^{1} \quad$ Isabel Dias $^{1} \quad$ Isabel Torgal ${ }^{1}$ \\ ${ }^{1}$ Department of Gynecology A, Centro Hospitalar e Universitário de \\ Coimbra, Coimbra, Portugal \\ Rev Bras Ginecol Obstet 2016;38:456-464. \\ Address for correspondence Eduardo Baptista, MD, Department of \\ Gynecology A, Centro Hospitalar e Universitário de Coimbra, Praceta \\ Prof. Mota Pinto, 3000-075, Coimbra, Portugal \\ (e-mail: eduardomcbaptista@yahoo.com).
}

\author{
Abstract \\ Keywords \\ - laparoscopy \\ - gynecologic surgery \\ - minimally invasive \\ surgery \\ - mayer-rokitansky- \\ küster-hauser \\ syndrome \\ - androgen \\ insensitivity \\ syndrome \\ - sexuality
}

Purpose To evaluate the anatomic and functional results of a laparoscopic modified Vecchietti technique for the creation of a neovagina in patients with congenital vaginal aplasia.

Methods Retrospective study of nine patients with congenital vaginal aplasia submitted to the laparoscopic Vecchietti procedure, in our department, between 2006 and 2013. The anatomical results were evaluated by assessing the length, width and epithelialization of the neovagina at the postoperative visits. The functional outcome was evaluated using the Rosen Female Sexual Function Index (FSFI) questionnaire and comparing the patients' results to those of a control group of 20 healthy women. The statistical analysis was performed using SPSS Statistics version 19.0 (IBM, Armonk, NY, USA), Student t-test, Mann-Whitney $\mathrm{U}$ test and Fisher exact test.

Results The condition underlying the vaginal aplasia was Mayer-Rokitansky-KüsterHauser syndrome in eight cases, and androgen insensitivity syndrome in one case. The average preoperative vaginal length was $2.9 \mathrm{~cm}$. At surgery, the mean age of the patients was 22.2 years. The surgery was performed successfully in all patients and no intra or postoperative complications were recorded. At the first postoperative visit (6 to 8 weeks after surgery), the mean vaginal length was $8.1 \mathrm{~cm}$. In all cases, the neovagina was epithelialized and had an appropriate width. The mean FSFI total and single domain scores did not differ significantly from those of the control group: 27.5 vs. 30.6 (total); 4.0 vs. 4.2 (desire); 4.4 vs. 5.2 (arousal); 5.2 vs. 5.3 (lubrication); 4.2 vs. 5.0 (orgasm); 5.3 vs. 5.5 (satisfaction) and 4.4 vs. 5.4 (comfort).

Conclusions This modified laparoscopic Vecchietti technique is a simple, safe and effective procedure, which allows patients with congenital vaginal aplasia to have a satisfactory sexual activity, comparable to that of normal controls.
DOI http://dx.doi.org/ $10.1055 / \mathrm{s}-0036-1593775$. ISSN $0100-7203$.
Copyright $\odot 2016$ by Thieme Publicações License terms Ltda, Rio de Janeiro, Brazil
(1) $\Theta \circledast$ 


\section{Resumo}

\section{Palavras-chave}

- laparoscopia

- cirurgia ginecológica

- cirurgia minimamente invasiva

- síndrome de mayerrokitansky-kusterhauser

- síndrome de insensibilidade aos andrógenos

- sexualidade
Objetivo Avaliar os resultados anatômicos e funcionais da técnica laparoscópica modificada de Vecchietti para a criação de uma neovagina em pacientes com aplasia vaginal congênita.

Métodos Estudo retrospectivo de nove pacientes com aplasia vaginal congênita submetidas à técnica laparoscópica modificada de Vecchietti, no nosso departamento, entre 2006 e 2013. Os resultados anatômicos foram aferidos através da avaliação do comprimento, largura e reepitelização da neovagina nas consultas pós-operatórias. Os resultados funcionais foram avaliados com recurso à versão em português do questionário Female Sexual Function Index de Rosen, comparando os resultados das pacientes aos de um grupo de controle de 20 mulheres saudáveis. A análise estatística foi realizada utilizando o programa SPSS Statistics versão 19.0), o teste t de Student, teste $\mathrm{U}$ de Mann-Whitney e teste exato de Fisher.

Resultados A etiologia subjacente à aplasia vaginal foi a síndrome de Mayer-Rokitansky-Küster-Hauser em oito casos, e a síndrome de insensibilidade aos andrógenos em um caso. O comprimento vaginal médio pré-operatório era de $2,9 \mathrm{~cm}$. À data da cirurgia, a média de idade das pacientes era de 22,2 anos. A cirurgia foi realizada com sucesso em todos os casos, sem registo de complicações intra ou pós-operatórias. $\mathrm{Na}$ primeira avaliação pós-operatória (6 a 8 semanas após a cirurgia), o comprimento vaginal médio foi de $8,1 \mathrm{~cm}$. Em todos os casos, a neovagina estava reepitelizada e com amplitude adequada. As pontuações médias, total e de cada domínio, obtidas no questionário de avaliação da função sexual não diferiram significativamente das do grupo controle: 27,5 vs 30,6 (total); 4.0 vs 4.2 (desejo); 4,4 vs 5,2 (excitação); 5,2 vs 5,3 (lubrificação); 4,2 vs 5,0 (orgasmo); 5,3 vs 5,5 (satisfação) e 4,4 vs 5,4 (conforto). Conclusões A técnica laparoscópica modificada de Vecchietti é um procedimento simples, seguro e eficaz, permitindo às pacientes com aplasia vaginal congênita uma atividade sexual satisfatória, comparável à dos controles normais.

\section{Introduction}

Congenital vaginal aplasia is a rare condition, with an incidence of 1 in 4,500 female live births. ${ }^{1}$ It usually occurs as part of Mayer-Rokitansky-Küster-Hauser (MRKH) syndrome, or, less frequently, as part of androgen insensitivity syndrome, Swyer syndrome or Turner syndrome.

First described by Mayer ${ }^{2}$ in 1829 , MRKH syndrome's prevalence ranges between $1: 4,000$ and 1:10,000 females. It is caused by embryologic growth failure of the Müllerian ducts, with resultant agenesis or underdevelopment of the vagina, uterus or both. The vaginal canal is absent or markedly shortened and blind-ended, without a cervix at the vaginal apex. A single midline uterine remnant or uterine horns can exist. The ovaries are anatomically and functionally normal ${ }^{3}$ and so patients with MRKH syndrome have a normal female phenotype, with normal secondary sexual characteristics and external genitalia, and normal hormonal profile. They have a normal 46, XX karyotype. These patients typically present with primary amenorrhea in adolescence.

Androgen insensitivity syndrome (AIS), formerly known as testicular feminization, affects 1 in 25,000 female newborns. ${ }^{4}$ It is a recessive $\mathrm{X}$ chromosome-linked hereditary disorder resulting in complete or partial androgen receptor function loss. These individuals have 46, XY karyotype. Their gonads are testes and produce normal androgens, but the lack of functional androgen tissue receptors results in a female phenotype. External genitalia may range from normal female genitalia with normal labia, clitoris and vaginal introitus, to undervirilized male genitalia with hypospadias and/or micropenis. These patients have sparse or no pubic and axillary hair, but due to peripheral conversion of circulating androgens to estrogens have normal breast development. Usually the vagina is underdeveloped and the uterus, cervix and fallopian tubes are absent because of intrauterine production of Müllerian inhibiting substance by the testes.

Numerous techniques have been described for the creation of a neovagina, including non-surgical and surgical methods that would allow sexual intercourse and healthy sexual relationships.

The non-surgical approach was first used by Frank ${ }^{5}$ in 1938 , developing the principles described by Amussat ${ }^{6}$ in 1935 . This technique requires patients to manually place successive blunt dilators on the vaginal dimple for 30 minutes to 2 hours per day during several months, using pressure to create the new vaginal canal. The American College of Obstetricians and Gynecologists (ACOG) still considers this as the appropriate first-line approach in most patients, particularly in mature and highly motivated patients who, wishing to avoid surgery, are willing to continue long-term dilatation. ${ }^{3}$

Numerous surgical techniques can be used to create a neovagina, most of them using autologous or heterologous 
tissues. Amnion membrane, ${ }^{7}$ dura mater from cadaver, ${ }^{8}$ myocutaneous, fasciocutaneous and labia minora flaps ${ }^{9}$ have been used for this purpose, but the most frequently used tissues are split-thickness skin grafts (Abbé-McIndoe operation), ${ }^{10}$ peritoneum (Davydov procedure) ${ }^{11}$ and intestinal segments (ileum, cecum or, more commonly, the sigmoid colon). Recent publications have described the use of artificial dermis and recombinant growth factor, ${ }^{12}$ autologous buccal mucosa ${ }^{13}$ and in-vitro cultured vaginal tissue ${ }^{14}$ to create the new vagina.

In 1965 , Vecchietti ${ }^{15}$ proposed a technique in which a continuous progressive pressure was exerted by an acrylic olive applied to the vaginal dimple, using the principles of Frank's dilator method. Two threads are attached to the olive, pass through the vesicorectal space, course subperitoneally and connect transabdominally to a traction device mounted on the abdominal wall. Constant traction is exercised on the olive from above by the traction device to produce $1-1.5 \mathrm{~cm}$ of invagination per day, creating a neovagina in $\sim 7-9$ days.

Unfortunately, this technique required a laparotomy and a prolonged postoperative stay. But, in 1992, the first experiences with Vecchietti operation using a laparoscopic approach were described and showed similar results to those of the original technique. ${ }^{16}$

In our department, the laparoscopic Vecchietti operation has been performed since 2006 for the creation of a neovagina in patients with vaginal aplasia. This study aims to evaluate the anatomic and functional results of all patients submitted to this procedure in our institution.

\section{Methods}

A retrospective assessment of the clinical records of all nine patients submitted to the laparoscopic Vecchietti procedure, in our department, between 2006 and 2013, was performed.

The data collected included the underlying condition associated to vaginal aplasia, age at diagnosis, body mass index (BMI), associated malformations, preoperative vaginal length, age at surgery, operating time, intra and postoperative complications, duration of postoperative hospital stay and vaginal length at first postoperative visit (6-8 weeks after surgery).

The surgical technique used in all cases was a laparoscopic Vecchietti-based procedure using vaginoabdominal blunt perforation without vesicorectal tunneling, according to the method described by Brucker et al. ${ }^{17}$

A specific instrument set was used, comprising a traction device, a pluggable segmented dummy, one straight and two curved thread-bearing needles and vaginal dummies for individual use after the traction phase, all developed by Storz (Karl Storz Endoscopy, Tuttlingen, Germany).

Preoperative care included thrombosis prophylaxis with low molecular weight heparin, antibiotic prophylaxis with cefazolin and intestinal preparation. Immediately before surgery, an epidural catheter is placed for postoperative analgesia.

With the patient in lithotomy position and under general anesthesia, the first step is to empty the bladder by cathe- terization. Then, the traction device is temporarily placed on the patient's abdomen, immediately below the navel, and the points at which the threads will exit are marked on the skin. Adequate pneumoperitoneum is obtained and a laparoscope is introduced via the transumbilical route, so that diagnostic examination of the abdominal and pelvic cavity is performed, and then a suprapubic auxiliary trocar is introduced.

The next step, and the most delicate one, is the perforation of the vaginal dimple without tunneling of the vesicorectal space. The straight thread guide, with the two threads attached to the segmented dummy, is inserted under the surgeon's index finger that pushes the vaginal dimple toward the abdomen, while two other fingers deviate the rectum dorsally. During this step, the rudimentary uterine ridge, or the union of the uterosacral ligaments, is drawn upwards, ventrally and cranially to ensure that the bladder is not lying over the point of perforation ( - Fig. 1). Intra-abdominally, the threads are detached from the straight thread guide, which is then removed (-Fig. 2).

After this step, a cystoscopy is performed to confirm that there was no bladder injury and to assist the placement of a suprapubic urinary drain.

The curved thread guides are inserted at the previously marked points on the abdominal wall and advanced subperitoneally, passing in front of the ureter and the external iliac complex until just in front of the inserted threads. One of these threads is hooked into the curved thread guide, which is then pulled back, placing the thread subperitoneally until exiting through the abdominal wall (-Fig. 3). The same procedure is repeated on the other side (-Fig. 4).

Finally, the abdominal ends of the threads are attached to the traction device under slight tension and then, these are tensioned to the maximum while the pluggable segmented dummy is guided, simultaneously, into the vaginal dimple (-Fig. 5).

For the next 6 to 8 days, the tensioning procedure is repeated daily ( $\sim 1 \mathrm{~cm}$ per day), pulling the dummy slowly upwards, following the virtual axis of the vagina, according to the patient's tolerance. This subsequent traction is gradual and progressive, as excessive traction may cause necrosis of the foveal epithelium, whereas limited traction would- not allow lengthening of the neovagina. During this period, analgesia is administered through the epidural catheter, the patient's nutrition is exclusively parenteral and the suprapubic urinary catheter is kept.

When sufficient vaginal depth is achieved $(7-10 \mathrm{~cm})$, the traction device, the segmented dummy and the tension threads are removed. Both the epidural catheter and the suprapubic urinary drain are withdrawn, and oral nutrition is started.

Before hospital discharge, all patients are instructed to use a vaginal dummy 24 hours a day, during 6 months, to prevent secondary shrinkage. The vaginal dummy should be covered with an estrogen containing cream to facilitate introduction and promote epithelialization.

Clinical follow-up was planned at 6-8 weeks, 3, 6 and 12 months post-surgery and every year thereafter. 


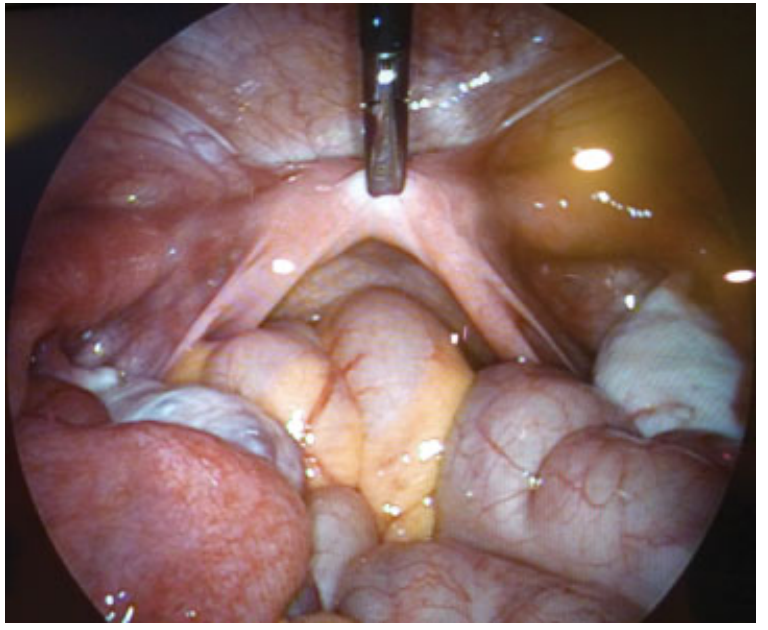

Fig. 1 Perforation of the vaginal dimple: the rudimentary uterine ridge is drawn ventrally and cranially to avoid bladder injury.

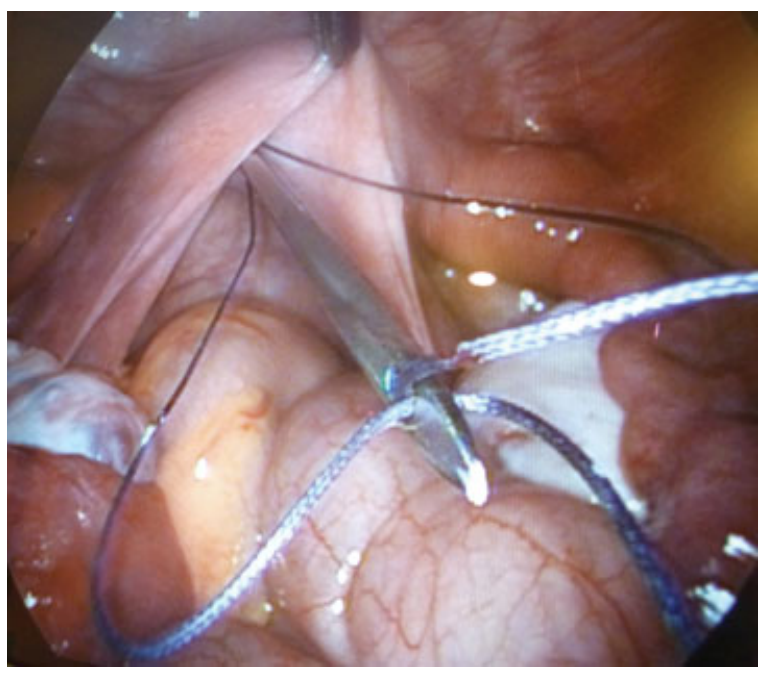

Fig. 2 Perforation of the vaginal dimple: the straight thread guide with the two threads positioned intraperitoneally.



Fig. 3 Positioning of the threads: curved thread guide advanced subperitoneally into the abdominal cavity, hooking one of the threads, which will be pulled back subperitoneally, until exiting through the abdominal wall.

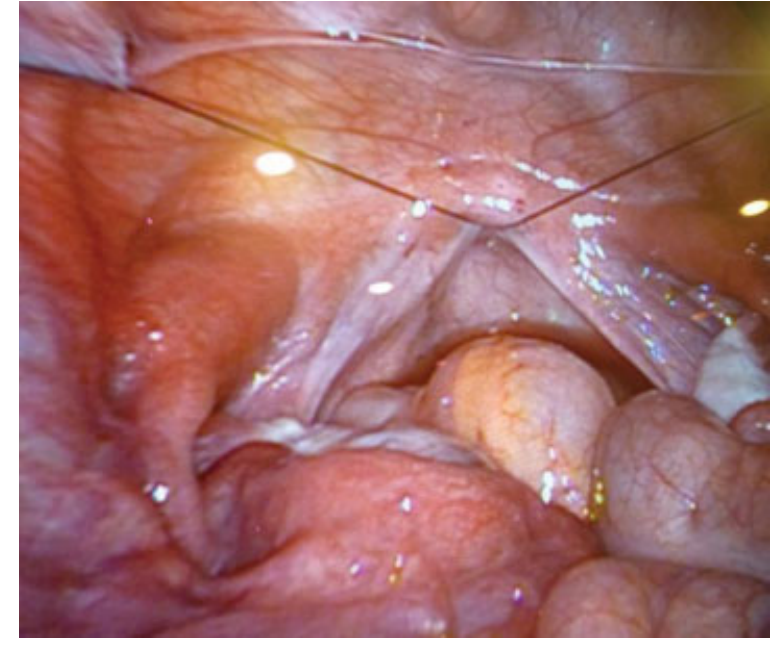

Fig. 4 Final internal aspect: Tension threads attached to vaginal dummy coursing subperitoneally.



Fig. 5 Final external aspect: The traction device placed on the lower abdominal wall with both threads attached and the segmented vaginal dummy in the vaginal dimple.

After the first postoperative visit, sexual intercourse was encouraged if the neovagina was epithelialized. If regular sexual activity was undertaken, the vaginal dummy was only used during the night from 6 months postoperative and stopped being used one year after the surgery.

The anatomical results were evaluated by measuring the length of the neovagina at the postoperative visits. The width of the vagina was also assessed. It was considered appropriate when easy introduction of two fingers along the entire length of the vagina was allowed. 
The functional results were rated using a Portuguese version of the Rosen Female Sexual Function Index (FSFI) questionnaire. ${ }^{18}$ This is a validated test for the evaluation of female sexual function, which consists of 19 questions in $\sim 6$ main domains: desire (2 questions), arousal (4 questions), lubrication (4 questions), orgasm (3 questions), satisfaction (3 questions) and comfort/pain (3 questions). The overall FSFI score ranges between 2 and 36 and according to Rosen's study, which concluded that 30 was the average score in a normal population, the sexual function was considered good when the total FSFI score was $\geq 30$, satisfactory when $>23$ but $<30$ and poor if $\leq 23$.

The FSFI questionnaire was also answered by a control group of 20 medical students, sexually active and with no known health problems.

The statistical analysis was performed using SPSS Statistics version 19.0 (IBM, Armonk, NY, USA). The continuous variables in both groups were characterized using the mean, standard deviation, minimum and maximum values. The Student t-test was used to compare means between cases and controls, and the Mann-Whitney $U$ test was used to compare values distribution when the assumptions for Student t-test were not satisfied. The normal distribution of values for these variables and the equality of their variances were tested using the Shapiro-Wilk and Levene tests, respectively. Categorical variables were characterized by absolute and relative frequencies. The differences in proportions between cases and controls were evaluated using the Fisher exact test (in accordance to the Cochran rules). The significance level used in this analysis was $5 \%$.

All procedures performed in this study were in accordance with the ethical standards of the institutional research committee, and with the 1964 Helsinki declaration and its later amendments.

Informed consent was obtained from all individual participants included in the study.

\section{Results}

In our department, between March 2006 and December 2013, a total of nine patients were submitted to the laparoscopic modified Vecchietti operation according to the technique described previously.

The mean age of the patients at surgery was 22.2 years. The conditions underlying the vaginal aplasia were MRKH syndrome in 8 cases, and AIS in the remaining case. The mean age at which the MRKH syndrome was diagnosed was 17.1 years and the only case of AIS was diagnosed at birth. None of the patients had associated urinary tract or kidney anomalies, other major comorbidities, or prior pelvic surgeries. One patient had undergone a previous vaginal reconstructive surgery in another institution, but the technique used was unknown. The average BMI at surgery was $21.6 \mathrm{~kg} / \mathrm{m}^{2}$ and none of the patients was obese (BMI $\geq 30 \mathrm{Kg} / \mathrm{m}^{2}$ ).

Preoperatively, the mean vaginal length was $2.9 \mathrm{~cm}$. Two patients reported having had sexual intercourse prior to surgery, which was classified as being unsatisfactory, in both cases.
The surgery was performed by the same surgeon in all cases, with exception of the most recent one. The procedure was completed successfully in all the patients with a mean operative time of 72.5 minutes. One of the patients (with AIS) was also submitted to nymphoplasty and urethral transposition at the same surgical time. This surgery had a total duration of 195 minutes and it was excluded when calculating the mean operative time.

No intra or postoperative complications were recorded. The mean duration of traction phase was 6.7 days and average hospital stay after surgery 8.4 days. The mean follow-up time was 53.2 months and none of the patients was lost to follow-up. At the first postoperative visit, which took place 6 to 8 weeks after surgery, the mean vaginal length was $8.1 \mathrm{~cm}$. In all nine cases, the neovagina was mostly epithelialized and had an appropriate width, allowing easy introduction of two fingers. Thus, all the patients were encouraged to start sexual activity.

To assess the quality of sexual function, the patients answered the FSFI questionnaire $\geq 12$ months after surgery, at a mean postoperative time of 40.2 months. The patients were, on average, 25.6 years old at the time they completed the FSFI test. These results were compared with those of a control group constituted by 20 medical students, with a mean age of 24.1 years, which did not differ significantly from the mean age of the patients at the time they answered the FSFI questionnaire ( $p=0.806$, using the Mann-Whitney U test).

The patients' anatomic and functional results are summarized in - Table 1. The mean FSFI scores obtained by the 9 patients in the 6 different individual domains were: 4.0 (desire); 4.4 (arousal); 5.2 (lubrication); 4.2 (orgasm); 5.3 (satisfaction) and 4.4 (comfort). The average overall FSFI score was 27.5, which was considered satisfactory. - Table 2 shows the single domain and total FSFI scores in the 9 patients, compared with 20 normal controls. The classification of sexual function, according to the FSFI total score, in both patients' and control group, is shown in - Table 3.

\section{Discussion}

In 1992, Gauwerky et $\mathrm{al}^{16}$ first described a technique that applied the principles of Vecchietti operation to laparoscopy with optimal results. Since then, this laparoscopic approach of the Vecchietti procedure has evolved, both in its surgical technique and instrumentation.

In our department, since the first surgery in 2006, a specific instrument set developed by Storz has been used, different from the original Vecchietti's traction device and acrylic olive. The pluggable segmented dummy used instead of the original olive allows the creation of a wider neovagina, and therefore is associated with minor discomfort at its removal, reduction of postoperative vaginal bleeding and easier use of the vaginal dilators after surgery. The traction device has all edges rounded and only flat, smooth surfaces contact the patient's skin, eliminating the need for cushioning and avoiding lesions to the abdominal surface. A single 
Table 1 Preoperative characteristics, anatomic and functional results of the patients

\begin{tabular}{|c|c|c|c|c|c|c|c|c|c|c|c|}
\hline \multirow[t]{2}{*}{ Case } & \multirow{2}{*}{$\begin{array}{l}\text { Underlying } \\
\text { condition }\end{array}$} & \multirow{2}{*}{$\begin{array}{l}\text { Age at surgery } \\
\text { (years) }\end{array}$} & \multirow{2}{*}{$\begin{array}{l}\text { Preoperative } \\
\text { VL }(\mathrm{cm})\end{array}$} & \multirow{2}{*}{$\begin{array}{l}\text { Postoperative } \\
\text { VL }(\mathrm{cm})\end{array}$} & \multicolumn{7}{|c|}{ FSFI score } \\
\hline & & & & & D & $A$ & $\mathrm{~L}$ & 0 & $S$ & $C$ & Total \\
\hline 1 & MRKH & 34 & NR & 7.5 & 3.6 & 3.3 & 6 & 3.6 & 5.6 & 1.6 & 23.7 \\
\hline 2 & MRKH & 19 & 4 & 8 & 4.8 & 3.9 & 4.2 & 3.2 & 4 & 4 & 24.1 \\
\hline 3 & MRKH & 19 & 1 & 6 & 5.4 & 5.4 & 5.7 & 6 & 6 & 6 & 34.5 \\
\hline 4 & MRKH & 21 & 3 & 8 & 4.2 & 4.2 & 4.8 & 3.2 & 5.2 & 5.6 & 27.2 \\
\hline 5 & AIS & 17 & 5 & 9 & 5.4 & 5.1 & 6 & 4.4 & 6 & 4.8 & 31.7 \\
\hline 6 & MRKH & 36 & 4 & 8.5 & 1.8 & 5.4 & 6 & 6 & 6 & 6 & 31.2 \\
\hline 7 & MRKH & 18 & 4.5 & 9.5 & 2.4 & 1.5 & 4.2 & 1.2 & 3.6 & 3.2 & 16.1 \\
\hline 8 & MRKH & 17 & 0.5 & 7 & 3.6 & 5.4 & 4.2 & 5.6 & 5.2 & 2.8 & 26.8 \\
\hline 9 & MRKH & 19 & 1.5 & 9 & 4.8 & 5.7 & 6 & 4.4 & 6 & 5.6 & 32.5 \\
\hline
\end{tabular}

NR: not recorded; D: desire; A: arousal; L: lubrication; O: orgasm; S: satisfaction; C: comfort (pain).

Abbreviations: FSFI, Female Sexual Function Index; MRKH, Mayer-Rokitansky-Küster-Hauser; VL, vaginal length.

Table 2 Single domain and total FSFI scores

\begin{tabular}{|l|c|c|c|}
\hline & Patients $(\boldsymbol{n}=\mathbf{9})$ & Controls $(\boldsymbol{n}=20)$ & $\boldsymbol{p}$ value \\
\hline Desire & $4.0 \pm 1.3[5.4-1.8]$ & $4.2 \pm 1.1[6-1.2]$ & $0.632^{*}$ \\
\hline Arousal & $4.4 \pm 1.4[5.7-1.5]$ & $5.2 \pm 0.7[6-3.9]$ & $0.144^{*}$ \\
\hline Lubrication & $5.2 \pm 0.9[6-4.2]$ & $5.3 \pm 0.6[6-4.2]$ & $0.789^{\dagger}$ \\
\hline Orgasm & $4.2 \pm 1.6[6-1.2]$ & $5.0 \pm 1.2[6-1.2]$ & $0.138^{*}$ \\
\hline Satisfaction & $5.3 \pm 0.9[6-3.6]$ & $5.5 \pm 0.6[6-4.0]$ & $0.823^{\dagger}$ \\
\hline Comfort (pain) & $4.4 \pm 1.6[6-1.6]$ & $5.4 \pm 0.8[6-3.6]$ & $0.109^{\dagger}$ \\
\hline Total & $27.5 \pm 5.7[34.5-16.1]$ & $30.6 \pm 3.9[36-21.4]$ & $0.101^{*}$ \\
\hline
\end{tabular}

*Student's t-test; ${ }^{\dagger}$ Mann-Whitney U test.

Abbreviation: FSFI, Female Sexual Function Index.

traction pivot enables greater simplicity in tightening the threads, applying even, stepwise tension on both threads and ensuring that the segmented dummy is pulled in only one direction, avoiding dehiscence and tearing of the neovagina. ${ }^{17,19}$

In all nine surgical procedures, the technique described by Brucker et al $^{17}$ was performed using only blunt perforation of the vaginal dimple and vesicorectal septum, from vaginal to abdominal route, with the straight thread-bearing needle. This is the most important step of the procedure, and it is essential that the rudimentary uterine ridge or the union of the uterosacral ligaments is drawn upwards, ventrally and cranially, with a laparoscopic forceps to avoid bladder perforation. Simultaneously, the surgeon's fingers move the rectum dorsally to prevent rectal injury. If necessary, the direction of perforation through the vaginal dimple can be diaphanoscopically assessed with simultaneous cystoscopy and laparoscopy, but in our nine cases this procedure was never used, and cystoscopy was performed only after perforation of the vaginal dimple.

This technique dispenses with incision of the vesicorectal peritoneum and sharp tunneling of the space between the bladder and the rectum from abdominal to vaginal route, described by other authors. ${ }^{20,21}$ Thus, it requires only a single

Table 3 Classification of sexual function according to FSFI total score

\begin{tabular}{|l|c|c|c|}
\hline & Patients $(\boldsymbol{n}=\mathbf{9})$ & Controls $(\boldsymbol{n}=20)$ & $\boldsymbol{p}$ value* \\
\hline Good $(\geq 30)$ & $4(44.4 \%)$ & $14(70.0 \%)$ & 0.237 \\
\hline Satisfactory $(23.1-29.9)$ & $4(44.4 \%)$ & $5(25.0 \%)$ & 0.396 \\
\hline Poor $(\leq 23)$ & $1(11.1 \%)$ & $1(5.0 \%)$ & 0.532 \\
\hline
\end{tabular}

*Fisher's exact test.

Abbreviation: FSFI, Female Sexual Function Index. 
suprapubic ancillary trocar and eliminates the need for additional imaging tools such as rectoscopy ${ }^{20}$ or transvaginal ultrasound. $22-24$

The traction device is positioned on the patient's abdomen, as cranially as possible, with its superior border immediately below the navel. This positioning, instead of the original Vecchietti suprapubic positioning, allows the creation of a longer neovagina and prevents bladder injury by anterior displacement of the dummy when the direction of traction is too ventral. ${ }^{25,26}$

This optimized surgical technique for performance of the laparoscopic Vecchietti operation, along with the use of the recently developed instrument set, has demonstrated to be a safer, faster and more effective minimally invasive method for neovagina creation, when comparing to other, more traumatic, conventional laparoscopic Vecchietti-based techniques. $^{17}$

Despite the small size of the sample, the results of our study support these findings.

First, none of the described intra or postoperative complications associated to this procedure, such as urethra, bladder, intestine, rectum or iliac vessels injuries, vaginal bleeding, hematoma or fistula formation, peritonitis, urinary tract infection or postoperative fever, occurred in our nine patients. Also, no mechanical complications associated to the instrument set were recorded (for instance, snapping of the traction threads, slippage of the traction device, pressure lesions on the abdominal skin, dehiscence of the vagina resulting from uneven traction, displacement of the dummy toward the bladder or urethral necrosis).

Second, the mean duration of surgery was 72.5 minutes, which can be deemed quite satisfactory, considering that the reduced number of procedures performed in our department ( $\sim 1$ per year) did not allow the development of a learning curve and consequent shortening of operating times. Nevertheless, our mean operating time was inferior to that of other reports in which experienced surgical teams were performing conventional laparoscopic Vecchietti operation (with vesicorectal dissection) using non-optimized instruments. ${ }^{17,27,28}$ Again, when compared with other studies using conventional laparoscopic surgical and instrumental approach, our mean duration of traction (6.7 days) was shorter ${ }^{16,17,22,24,29}$, even though we have not used predistension in any of our 9 patients. A mean postoperative stay of 8.4 days may be considered acceptable, taking into account that the traction phase was always completed inpatient and that all patients (the majority living in distant locations) were only released when fully recovered.

Finally, we achieved satisfactory anatomic and functional global results, using this optimized surgical technique.

Anatomical success was obtained in all nine cases. The average vaginal length at 6 to 8 weeks after surgery was $8.1 \mathrm{~cm}$ and all 9 patients presented a neovagina $\geq 6 \mathrm{~cm}$ in length, allowing easy introduction of two fingers. We consider that from 6 to 8 weeks postoperative onwards, the vaginal length and width are more dependent on appropriate individual use of the postoperative vaginal dilators and regular sexual activity than on surgical technique. These anatomical results do not differ significantly from those reported on studies with lager samples. ${ }^{17,20,29,30}$

The main objective of the surgery is to provide women with vaginal aplasia the possibility of a quality sexual life, and so the present study gave particular emphasis on the evaluation of functional results. For this purpose, the FSFI questionnaire was answered by all 9 patients and also by a group of 20 healthy controls with similar mean age. The FSFI test was developed by Rosen in 2000 and has been validated for the assessment of female sexual function. ${ }^{18}$ It has proven to be a relevant and reproducible test and therefore was widely accepted. In our study, the FSFI questionnaire results revealed no statistically significant differences between the patients and controls regarding each single domain and total scores. Also the classification of sexual function according to the total FSFI score (good, satisfactory or poor) did not differ significantly between the two groups and was classified as poor in only one case on each group.

We consider that functional success was achieved in 8 of 9 patients (88.9\%). The remaining patient (case 7) obtained a total FSFI score of 16.1. However, her score in the lubrication domain, which may be less influenced by psychological issues, was quite satisfactory (4.2/6).

In literature, we found only another study ${ }^{27}$ in which there were no statistically significant differences between cases and controls in any of the six single domains, or in the total FSFI score.

Thus, our study demonstrates that the quality of sexual function in the group of patients with vaginal aplasia after creation of a neovagina by this laparoscopic modified Vecchietti technique is comparable to that of a group of healthy women in the same age bracket.

The ACOG states that non-surgical creation of a neovagina is the appropriate first line approach in most patients ${ }^{3}$ and Frank self-dilatation method is still successfully used nowadays. ${ }^{31,32}$ Presently, there are no controlled studies comparing the laparoscopic Vecchietti technique to Frank method. Obviously, the latter allows patients to avoid surgery and has few associated risks. However, it requires favorable anatomic conditions, namely a vaginal fovea with some depth, and persistent collaboration of the patient during the long period of time necessary to achieve an appropriate vaginal length. The Vecchietti laparoscopic technique implies a low-risk, minimally invasive surgical approach, but can be performed in almost all patients with congenital vaginal aplasia, allowing creation of an adequate vaginal length after only a few days of traction and requiring the use of postoperative vaginal dummies for a short period of time. Therefore, it prevents the physical and psychological distress associated to the lengthy and painful self-dilatation procedure.

Currently, there is no consensus in the literature concerning the best surgical option for neovagina creation to afford the best functional outcomes. Successful results with different vaginoplasty techniques have been described.

Historically, the Abbé-McIndoe operation ${ }^{10}$ has been the most common surgical procedure used for correction of vaginal aplasia since its publication, in 1938, and it still is the most widely used surgical technique in the United States. 
This procedure involves the dissection of the vesicorectal space, placement of a mold covered with a meshed splitthickness skin graft to line the vaginal space and diligent use of dilators postoperatively. The main disadvantages of this technique are the association with significant skin graft contracture, developing of fistulas, visible scar formation at the donor site with possibility of poor aesthetic results, and the high costs due to involvement of a plastic surgery team and long hospitalization. ${ }^{33}$

The use of an isolated segment of sigmoid colon for neovagina creation has been reported to yield satisfactory anatomic and functional outcomes. ${ }^{34-36}$ It is a more complex procedure, but has a low risk of neovaginal stenosis and dispenses with the use of postoperative vaginal dilatation. However, sigmoid vaginoplasty is a major surgical procedure and some authors report significant intra and postoperative complications, such as necrosis of the sigmoid graft, intestinal anastomosis dehiscence, neovagina prolapse, peritonitis, obstruction, colitis and adenocarcinoma of the neovagina. Also, persistent smelling vaginal discharge has been pointed as a major drawback. ${ }^{37-39}$

In 1969, Davydov ${ }^{11}$ described a procedure in which the patient's own pelvic peritoneum is used for vaginal reconstruction. It requires dissection of the vesicorectal space, abdominal mobilization of a segment of the peritoneum and its attachment to the introitus. ${ }^{11}$ This procedure is particularly useful in patients with abnormalities of the external genitalia due to its vaginal step and is suitable for creation of a neovagina in patients with previous unsuccessful vaginal surgery. The main disadvantages of this approach are the longtime need for dilators, poor lubrication of the neovagina, requiring the use of lubricants, and the risk of prolapse or fistula formation. ${ }^{40}$

The main advantage of the Vecchietti-based methods over the other surgical procedures is the creation of a neovagina with normal anatomy and histomorphology, ${ }^{41,42}$ allowing a satisfactory functionality and avoiding the morbidity associated to the use of extraneous tissues (such as skin, intestine or peritoneum), or the performance of plastic surgery causing visible scars. Also, the satisfying functional outcomes are achieved in a short period of time.

In conclusion, our experience supports the most recent literature data. This laparoscopic modified Vecchietti technique is a simple, fast, effective and low-risk procedure that allows the creation of a neovagina in the correct axis, with adequate size and secretory capacity, allowing women with congenital vaginal aplasia to initiate a normal sexual activity.

\section{References}

1 Capraro VJ, Gallego MB. Vaginal agenesis. Am J Obstet Gynecol 1976;124(1):98-107

2 Mayer CAJ. Über Verdoppelungen des Uterus und ihre Arten, nebst Bemerkungen über Hasenscharte und Wolfsrachen. J Chir Augenheilkd. 1829;13:525-565

3 Committee on Adolescent Health Care. Committee opinion: no. 562: müllerian agenesis: diagnosis, management, and treatment. Obstet Gynecol 2013;121(5):1134-1137
4 Oppelt P, Renner SP, Kellermann A, et al. Clinical aspects of Mayer-Rokitansky-Kuester-Hauser syndrome: recommendations for clinical diagnosis and staging. Hum Reprod 2006; 21(3):792-797

5 Frank RT. The formation of an artificial vagina without operation. Am J Obstet Gynecol 1938;35(6):1053-1055

6 Amussat JZ. Observation sur une opération de vagin artificiel pratiquée avec succèss par un nouveau procédé, suivie de quelques refléxions sur les vices de conformation du vagin. Gaz Med Paris. 1835;50:785-817

7 Brindeau A. Créeation d'un vagin artificiel à l'aide des membranes ovulaires d'un oeuf à terme. Gynecol Obstet. 1934;29:385-392

8 Confalonieri C. Neovagina con trapianto di dura-madre omologata liofilizzata. Gazz Sanit 1972;43(9):407-420

9 Hwang WY, Chang TS, Sun P, Chung TH. Vaginal reconstruction using labia minora flaps in congenital total absence. Ann Plast Surg 1985;15(6):534-537

10 McIndoe AH, Bannister JB. An operation for the cure of congenital absence of the vagina. J Obstet Gynaecol Br Emp 1938;45(3): 490-494

11 Davydov SN. [Colpopoeisis from the peritoneum of the uterorectal space]. Akush Ginekol (Mosk) 1969;45(12):55-57

12 Noguchi S, Nakatsuka M, Sugiyama Y, Chekir C, Kamada Y, Hiramatsu Y. Use of artificial dermis and recombinant basic fibroblast growth factor for creating a neovagina in a patient with Mayer-Rokitansky-Kuster-Hauser syndrome. Hum Reprod 2004;19(7):1629-1632

13 Lin WC, Chang CY, Shen YY, Tsai HD. Use of autologous buccal mucosa for vaginoplasty: a study of eight cases. Hum Reprod 2003;18(3):604-607

14 Panici PB, Bellati F, Boni T, Francescangeli F, Frati L, Marchese C. Vaginoplasty using autologous in vitro cultured vaginal tissue in a patient with Mayer-von-Rokitansky-Kuster-Hauser syndrome. Hum Reprod 2007;22(7):2025-2028

15 Vecchietti G. Creation of an artificial vagina in Rokitansky-KüsterHauser syndrome. Attual Ostet Ginecol 1965;11(2):131-147

16 Gauwerky JF, Wallwiener D, Bastert G. An endoscopically assisted technique for construction of a neovagina. Arch Gynecol Obstet 1992;252(2):59-63

17 Brucker SY, Gegusch M, Zubke W, Rall K, Gauwerky JF, Wallwiener D. Neovagina creation in vaginal agenesis: development of a new laparoscopic Vecchietti-based procedure and optimized instruments in a prospective comparative interventional study in 101 patients. Fertil Steril 2008;90(5):1940-1952

18 Rosen R, Brown C, Heiman J, et al. The Female Sexual Function Index (FSFI): a multidimensional self-report instrument for the assessment of female sexual function. J Sex Marital Ther 2000; 26(2):191-208

19 Fedele L, Bianchi S, Berlanda N, Fontana E, Bulfoni A, Borruto F. Laparoscopic creation of a neovagina with the laparoscopic Vecchietti operation: comparison of two instrument sets. Fertil Steril 2006;86(2):429-432

20 Fedele L, Bianchi S, Frontino G, Fontana E, Restelli E, Bruni V. The laparoscopic Vecchietti's modified technique in Rokitansky syndrome: anatomic, functional, and sexual long-term results. Am J Obstet Gynecol 2008;198(4):377.e1-377.e6

21 Folgueira G, Perez-Medina T, Martinez-Cortes L, et al. Laparoscopic creation of a neovagina in Mayer-Rokitansky-Küster-Hauser syndrome by modified Vecchietti's procedure. Eur J Obstet Gynecol Reprod Biol 2006;127(2):240-243

22 Busacca M, Perino A, Venezia R. Laparoscopic-ultrasonographic combined technique for the creation of a neovagina in MayerRokitansky-Kuster-Hauser syndrome. Fertil Steril 1996;66(6): 1039-1041

23 Csermely T, Halvax L, Sárkány A, et al. Sexual function after modified laparoscopic Vecchietti's vaginoplasty. J Pediatr Adolesc Gynecol 2011;24(3):147-152 
24 Giacalone PL, Laffargue F, Faure JM, Deschamps F. Ultrasoundassisted laparoscopic creation of a neovagina by modification of Vecchietti's operation. Obstet Gynecol 1999;93(3):446-448

25 Fedele L, Bianchi S, Tozzi L, Borruto F, Vignali M. A new laparoscopic procedure for creation of a neovagina in Mayer-RokitanskyKuster-Hauser syndrome. Fertil Steril 1996;66(5):854-857

26 Pelzer V, Graf M. [The segmented phantom insert for the formation of a neovagina according to Vecchietti]. Geburtshilfe Frauenheilkd 1989;49(11):977-980 German.

27 Abramowicz S, Oden S, Joutel N, Roman H, Gromez A, Marpeau L. Laparoscopic creation of a neovagina by Vecchietti's technique: anatomic and functional results. Gynecol Obstet Fertil 2013;41(1):4-9

28 Keckstein J, Kandolf O, Rauter G, Hudelist G. Long-term outcome after laparoscopic creation of a neovagina in patients with MayerRokitansky-Küster-Hauser syndrome by a modified Vecchietti procedure. Gynecol Surg 2008;5(1):21-25

29 Fedele L, Bianchi S, Zanconato G, Raffaelli R. Laparoscopic creation of a neovagina in patients with Rokitansky syndrome: analysis of 52 cases. Fertil Steril 2000;74(2):384-389

30 Rall K, Schickner MC, Barresi G, et al. Laparoscopically assisted neovaginoplasty in vaginal agenesis: a long-term outcome study in 240 patients. J Pediatr Adolesc Gynecol 2014;27(6):379-385

31 Ismail-Pratt IS, Bikoo M, Liao LM, Conway GS, Creighton SM. Normalization of the vagina by dilator treatment alone in Complete Androgen Insensitivity Syndrome and Mayer-RokitanskyKüster-Hauser syndrome. Hum Reprod 2007;22(7):2020-2024

32 Jasonni VM, La Marca A, Naldi S, Matonti G, D’Anna R. The management of vaginal agenesis: report of 104 cases. Fertil Steril 2007;88(6):1653-1656

33 Keser A, Bozkurt N, Taner OF, Sensöz O. Treatment of vaginal agenesis with modified Abbé-McIndoe technique: long-term follow-up in 22 patients. Eur J Obstet Gynecol Reprod Biol 2005;121(1):110-116
34 Cai B, Zhang JR, Xi XW, Yan Q, Wan XP. Laparoscopically assisted sigmoid colon vaginoplasty in women with Mayer-RokitanskyKuster-Hauser syndrome: feasibility and short-term results. BJOG 2007;114(12):1486-1492

35 Communal PH, Chevret-Measson M, Golfier F, Raudrant D. Sexuality after sigmoid colpopoiesis in patients with Mayer-Rokitansky-Kuster-Hauser Syndrome. Fertil Steril 2003;80(3):600-606

36 Darai E, Toullalan O, Besse O, Potiron L, Delga P. Anatomic and functional results of laparoscopic-perineal neovagina construction by sigmoid colpoplasty in women with Rokitansky's syndrome. Hum Reprod 2003;18(11):2454-2459

37 Karateke A, Haliloglu B, Parlak O, Cam C, Coksuer H. Intestinal vaginoplasty: seven years' experience of a tertiary center. Fertil Steril 2010;94(6):2312-2315

38 Khen-Dunlop N, Lortat-Jacob S, Thibaud E, Clément-Ziza M, Lyonnet S, Nihoul-Fekete C. Rokitansky syndrome: clinical experience and results of sigmoid vaginoplasty in 23 young girls. J Urol 2007;177(3):1107-1111

39 Lima M, Ruggeri G, Randi B, et al. Vaginal replacement in the pediatric age group: a 34-year experience of intestinal vaginoplasty in children and young girls. J Pediatr Surg 2010;45(10): 2087-2091

40 Fedele L, Frontino G, Restelli E, Ciappina N, Motta F, Bianchi S. Creation of a neovagina by Davydov's laparoscopic modified technique in patients with Rokitansky syndrome. Am J Obstet Gynecol 2010;202(1):33.e1-33.e6

41 Belleannée G, Brun JL, Trouette $\mathrm{H}$, et al. Cytologic findings in a neovagina created with Vecchietti's technique for treating vaginal aplasia. Acta Cytol 1998;42(4):945-948

42 Fedele L, Bianchi S, Berlanda N, et al. Neovaginal mucosa after Vecchietti's laparoscopic operation for Rokitansky syndrome: structural and ultrastructural study. Am J Obstet Gynecol 2006; 195(1):56-61 